\title{
Allocation of primary sources for safflower (Carthamus) selection in Uzbekistan
}

\author{
Abdumalik Rustamov ${ }^{1, *}$, Makhfurat Amanova ${ }^{1}$, Bekhzod Rustamov ${ }^{1}$, and Abror Khasanov ${ }^{1}$ \\ ${ }^{1}$ Tashkent State Agrarian University, University str., 2, Tashkent province, Uzbekistan, 100140
}

\begin{abstract}
Based on a comprehensive study of 100 samples of safflower from the world gene pool for three years, the results of the selection of primary sources for different areas of selection (growth period, 1 plant yield, 1000 seed weight, oil content) are covered. Primary sources for different areas of selection have been identified on the basis of the study of the early maturity of seed samples, seed size, oil content in seeds, the study of the correlation between complex traits and the main economic traits. Correlation between major crop characteristics such as safflower vegetation period, main stem height, number of primary, secondary and lateral branches, total number of pods per plant, number of seeds per pod, plant yield, weight of 1000 seeds, oil content in seeds were studied. The highest correlation was found between the length of the main stem and the length to the first branch $(\mathrm{r}=0.84)$ and the total number of baskets in one plant with the number of secondary side branches in it $(r=0.90)$.
\end{abstract}

\section{Introduction}

In Uzbekistan, dry land is cultivated annually on 65-70 thousand hectares of dry land; with an average yield of 6-7 q/ha [1-3]. In this country, a number of studies has been conducted on the investigation of the world collection of oilseeds, the selection of promising sources, processing, cultivation technology and diseases [4]. However, the selection work on the creation of early-maturing, high-yielding, large-seeded, high-yielding and dormant varieties that are adapted to the climatic conditions of the country, resistant to environmental stress factors, does not fully meet modern requirements. Until 2019, only Gallaorol, Milyutinsky (hereinafter, 114) and Nodir varieties are included in the state register. Therefore, the allocation of unique and promising primary sources for the selection process remains an urgent problem [5].

Cotton, grain, fruits, grapes, vegetables and melons are grown on the main irrigated areas of the country. For this reason, the opportunities to expand the cultivation of oilseeds on irrigated lands are limited, and the main focus is on dry areas. Of the oil-bearing crops, only safflower and flax can be grown in dry areas because they are cold-tolerant and drought-resistant $[6,7]$.

There are many types of oilseeds in the world, but in our country mainly cotton, sunflower, sorghum, peanut, sesame and flaxseed oil are imported, the main reason for

\footnotetext{
* Corresponding author: rustamov.abdumalik@mail.ru
} 
which is that the biology of these plants corresponds to our soil and climatic conditions and these species are economically justified $[4,8]$

The published literature provides information on the study of the collection of safflower, high-yielding, disease and pest-resistant varieties suitable for different soil and climatic conditions, changes in the amount of oil in the seeds.

Based on the study of the Safflower collection, 16 ridges and 5 varieties were selected on the basis of the highest height first horn, number of branches, number of buds and weight of 1000 seeds. The Remzibey variety was singled out for the highest seed yield, yield and oil consumption [9].

Oil with a high content of unsaturated fatty acids is obtained from safflower, but the oil content can change in water deficiency. The effect of three irrigation regimes $(60,75$, and $90 \%$ reduction in available soil moisture) on the oil content of safflower varieties (Kuseh, PI and IL111) was determined. Based on the results, the water shortage led to a sharp decrease in the saturated fatty acids in the oil content of the safflower varieties. It has been found that the quality of safflower oil can be improved with proper irrigation of safflower [10].

At the Aktyubin Agricultural Experiment Station a new, Akhram variety was created, which differs from the regionalized variety in terms of high ecological plasticity, economic and biological characteristics. Vegetation period of Akhram variety is 120-125 days, yield is $9-10 \%$ or $14-17 \mathrm{q} /$ ha on average, seeds are large, weight of 1000 seeds is $45-50 \mathrm{~g}$, yield is $37-38 \%$. When planted in the arid western regions of Kazakhstan, $380 \mathrm{~kg}$ of oil was extracted from 1 hectare, which was $90 \mathrm{~kg}$ higher than the control [1, 4].

In a study conducted by the Center for Plant Genetic Resources (PGRC) of Canada to study phenotypic diversity in 2331 flax samples, it was suggested that all varieties in Canada belong to two botanical diversities and use a traditional internal classification method to compare gene pools [5].

Yellow seed flax hermaplasma (Linum usitatissimum L.) was evaluated for agromorphological and qualitative characteristics. Among the 10 characters studied, maximum variability was observed in each plant $(7.44-9.85 \%)$. The smallest variability was observed in plant height $(0.23 \%)$ and oil content $(0.61 \%)$. Potential donors who could be used in the selection program were identified. The EC 41583 genotype has been proven to be one of the beneficial donors for the plant. The BSL-4 genotype was found to be a good donor in terms of fat content. It has been observed that plant branching has a direct and strong correlation with seed number and seed mass per plant yield [11-13].

Allocation of primary sources for the creation of new varieties of safflower resistant to stress factors of the external environment, acceleration of the process of analytical and synthetic selection is one of the current problems of scientific and practical importance. This situation motivates us to conduct scientific research in this area.

Thus, the main goal of our research is to isolate promising sources of safflower crop from the world collection for different areas of selection, to create new high-yielding, highfat varieties of seeds and to involve them in the selection process.

\section{Materials and methods}

The research was conducted in 2017-2019 in the field experimental fields of the Tashkent Regional Research Institute of Plant Genetic Resources, suitable for soil and climatic conditions. The object of research was 100 samples of safflower in the gene pool of the Research Institute of Plant Genetic Resources.

In the Safflower collection, the sections were planted in a row of five meters $\left(3.5 \mathrm{~m}^{2}\right)$, $70 \times 20 \mathrm{~cm}$. Safflower samples were studied in the first year study seedlings irreversibly, and in the second and third years with three repetitions. After every ten episodes, the standard 
variety "114" was placed. The following phenological observations were made during the growth period of the safflower crop: grass germination (10\%); full emergence of grasses (75\%); onset of flowering (10\%); full flowering (75\%); seed maturation (10\%); physiological maturation of seeds $(75 \%)$.

In the collection nursery, morphological features (height of the main stem, skeletal branches, color of the flower, and shape of the baskets) were studied when the plants entered the full (75\%) flowering stage. During the harvest, beometric measurements were carried out on 10 plants from each section. Under laboratory conditions, the crop residues collected from each compartment were cleaned of waste seeds, the total yield was determined, and the productivity of one plant was determined by dividing by the number of plants in the compartment. The weight of 1000 seeds of each sample and the amount of oil in the seeds were studied by the method of AI Ermakov $[1,2]$.

Statistical analysis of the study results in computer programs Excel 2010 and Statistica 7.0 for Windows, with a confidence interval of $0.95 \%$ calculated according to Dospekhov's method [1].

\section{Results and discussion}

Today, more than 450 specimens of safflower are kept alive in the plant gene pool of the Research Institute of Plant Genetic Resources, of which 100 specimens of safflower are involved in our research.

The standard variety is -114 , which is regionalized in the country. The growing period of this variety is 105 days, the height of the main stem is $60 \mathrm{~cm}$, the height to the fruit skeletal branches is $40 \mathrm{~cm}$, the number of fruit skeletal branches is 6 , the number of fruit baskets is 11 , the diameter of the harvest basket is $2 \mathrm{~cm}$, the average yield of one plant is 17 g. number 39 , the weight of 1000 seeds was $39 \mathrm{~g}$, the oil content of the seeds was $38 \%$.

In the second decade of March, the seeds of the collection nursery were sown in $3.5 \mathrm{~m}^{2}$ compartments in the fall, and on April 7-12, the seedlings were fully harvested.

Phenological observations were made during the growing season in the collection nursery. It was noted that the first flowers bloomed in 75-76 days after the full germination of grass in the model "114". 8 days before the template, k-25 (Uzbekistan), k-336 (USA), k-299, k-313, k-316, 317 (Mexico), k-303, k-337 (Spain), k- 339 (Portugal, k-477, k-478, k-479 (Kazakhstan) specimens were observed to have entered the flowering stage. The flowering process lasted 15-17 days per plant and 29 days in the collection nursery field.

As a result of studying the collection samples on morphological features, it was found that there are 15 specimens with strong thorns, 28 specimens with weak thorns and 57 specimens without thorns.

The color of the flower of the Safflower plant is one of the main selection traits, from which ecologically clean consumer dyes are obtained. This dye is widely used in coloring various confectionery, pasta and other food products. Of the samples involved in the study, 14 were bright yellow, 8 were yellow, 20 were orange and 58 were red.

For the livestock sector, the height of the stalk of the safflower plant is one of the main signs in the cultivation of tomorrow, vitamin fodder.

Four high-performance safflower samples (k-411 - Egypt, k-193 - Australia, k-351 Mexico, and k-262 - Poland) were selected from the safflower samples studied on the main stem height. The selected specimens were found to be $10-11 \mathrm{~cm}$ higher than the standard variety in terms of main stem height $(70-71 \mathrm{~cm})$.

According to the early ripening properties of safflower, k-299, k-313, k-316, k-317 (Mexico), k-303, k-337 (Spain), from the studied samples as k-339 (Portugal) and k-477, k478 , k-479 (Kazakhstan), in total, 10 samples were isolated. It was noted that the selected 
samples were 5-8 days earlier than the standard variety, 5-6 days earlier than the flowering stage, and physiologically mature 5-7 days earlier than the standard variety (Table 1).

Table 1. Main valuable economic features of the samples of safflower, selected on the basis of early maturity (2017-2019)

\begin{tabular}{|c|c|c|c|c|c|c|}
\hline \# & 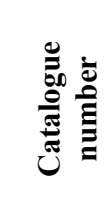 & 菢 & 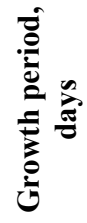 & 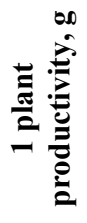 & 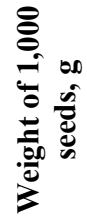 & 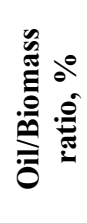 \\
\hline 1 & 114 (st) & Uzbekistan & 105 & 17 & 39 & 38 \\
\hline 2 & 299 & Mexico & 98 & 20 & 42 & 39 \\
\hline 3 & 313 & Mexico & 98 & 16 & 44 & 39 \\
\hline 4 & 316 & Mexico & 98 & 17 & 43 & 39 \\
\hline 5 & 317 & Mexico & 98 & 20 & 45 & 39 \\
\hline 6 & 303 & Spain & 100 & 15 & 45 & 37 \\
\hline 7 & 337 & Spain & 98 & 22 & 39 & 41 \\
\hline 8 & 339 & Portugal & 100 & 22 & 46 & 46 \\
\hline 9 & 477 & Kazakhstan & 100 & 18 & 46 & 37 \\
\hline 10 & 478 & Kazakhstan & 100 & 18 & 47 & 42 \\
\hline 11 & 479 & Kazakhstan & 100 & 14 & 41 & 36 \\
\hline
\end{tabular}

Samples k-229 k-317 (Mexico), k-337 (Spain) and k-339 (Portugal), selected on the basis of maturity, and also showed a result of 3-5 grams higher than the standard variety in terms of productivity. The selected early ripening k-339 (Portugal) sample matured 5 days earlier than the standard variety, with a higher yield per plant yield $(22 \mathrm{~g}), 1000$ seed weight ( $7 \mathrm{~g})$ and seed oil content (7\%). separated. The isolated specimens can be used as a primary source in the creation of early-maturing, high-yielding varieties. It was noted that 86 of the studied samples matured simultaneously with the standard variety (103-105), 4 (k54, k-66, k-176 and k-182 - 108-110) 3-5 days late.

A number of factors have been found in our multi-year studies to influence the growth period of early maturing specimens, and it has been observed that the vegetation duration increases from 10 to 30 days when nutrients and moisture are sufficient.

The yield elements in a plant include the number of crop baskets, the average number of seeds in a crop basket, and the productivity of one plant. As a result of the three-year study, high results were recorded in 37 samples per plant yield compared to the standard variety.

In these samples, the average yield per plant was found to be 20-33 grams. In the model "114" this figure was 17 grams. 
These samples can be used as promising sources in the creation of new, high-yielding varieties that are adapted to the climatic conditions of the country, resistant to environmental stress factors (Table 2).

Table 2. Main valuable economic characteristics of the sample of safflower isolated on the productivity of one plant (2017-2019)

\begin{tabular}{|c|c|c|c|c|c|c|}
\hline \# & 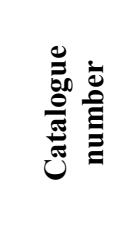 & 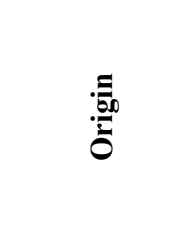 & 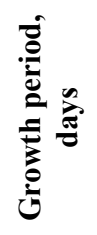 & 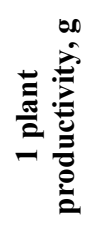 & 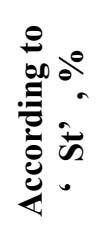 & 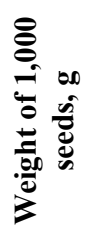 \\
\hline 1 & $114(\mathrm{st})$ & Uzbekistan & 105 & 17 & 100 & 39 \\
\hline 2 & 54 & Ethiopia & 110 & 25 & 147 & 45 \\
\hline 3 & 57 & Ethiopia & 110 & 31 & 182 & 45 \\
\hline 4 & 165 & Sudan & 108 & 33 & 194 & 42 \\
\hline 5 & 328 & USA & 105 & 27 & 159 & 39 \\
\hline 6 & 255 & Pakistan & 105 & 27 & 159 & 42 \\
\hline 7 & 321 & Mexico & 105 & 25 & 147 & 45 \\
\hline 8 & 322 & Mexico & 105 & 26 & 153 & 42 \\
\hline 9 & 323 & Mexico & 105 & 25 & 147 & 44 \\
\hline 10 & 332 & Mexico & 105 & 26 & 153 & 37 \\
\hline 11 & 351 & Mexico & 105 & 26 & 153 & 38 \\
\hline 12 & 352 & Mexico & 105 & 25 & 147 & 46 \\
\hline 13 & 386 & Mexico & 105 & 26 & 153 & 40 \\
\hline 14 & 143 & Poland & 105 & 39 & 229 & 43 \\
\hline 15 & 366 & Hungary & 105 & 25 & 147 & 41 \\
\hline 16 & 369 & Hungary & 105 & 25 & 147 & 39 \\
\hline 17 & 439 & Kazakhstan & 105 & 29 & 170 & 43 \\
\hline 18 & 458 & Kazakhstan & 105 & 25 & 147 & 42 \\
\hline 19 & 461 & Kazakhstan & 105 & 26 & 153 & 42 \\
\hline 20 & 463 & Kazakhstan & 105 & 26 & 153 & 43 \\
\hline
\end{tabular}




\begin{tabular}{|l|l|l|l|l|l|l|}
\hline 21 & 464 & Kazakhstan & 105 & 26 & 153 & 43 \\
\hline
\end{tabular}

Harvest baskets on a plant, the number of seeds in them, and the size of the seed are one of the main and important factors affecting productivity. The number of harvest baskets varies depending on the quality of the applied agro-technical measures (seedling thickness, planting time and feeding rate).

Of the 14 samples selected by number of harvest baskets, 2 (k-54, k-57) were from Ethiopia, 3 (k-266, k-227, k-228) were from the United States, and 3 (k-332, k-382, k-402) Mexico and 1 (k-165) Sudan, (k-209) Australia, (k-254) Pakistan, (k-355) Bangladesh, and (k-143) Poland. the number of baskets was 16-25, ie 16 in k-54 (Ethiopia), k-266, k-227 (USA), k-332, k-402 (Mexico), k-366 (Hungary) samples; k-254 (Pakistan), k-382 (Mexico) - 17 each; k-355 (Bangladesh) -18 each; k-57 (Ethiopia), k-165 (Sudan) -19 each; k-328 (USA) - 20 each and k-143 (Poland) - 25 baskets were found. This figure was 11 in the standard variety (Table 3 ).

Table 3. Main economic characteristics of the sample of safflower selected by the number of crop baskets per plant (2017-2019)

\begin{tabular}{|c|c|c|c|c|c|c|}
\hline$\#$ & 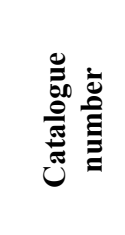 & 志 & 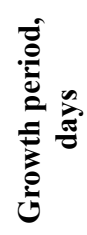 & 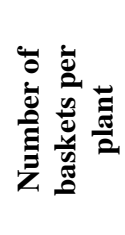 & 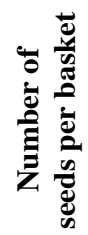 & 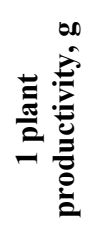 \\
\hline 1 & 114 (st) & Uzbekistan & 105 & 11 & 39 & 17 \\
\hline 2 & 54 & Ethiopia & 110 & 16 & 45 & 25 \\
\hline 3 & 57 & Ethiopia & 110 & 19 & 41 & 31 \\
\hline 4 & 165 & Sudan & 108 & 19 & 40 & 33 \\
\hline 5 & 209 & Australia & 105 & 16 & 38 & 21 \\
\hline 6 & 266 & USA & 105 & 16 & 39 & 20 \\
\hline 7 & 227 & USA & 105 & 16 & 43 & 24 \\
\hline 8 & 328 & USA & 105 & 20 & 44 & 27 \\
\hline 9 & 254 & Pakistan & 105 & 17 & 35 & 18 \\
\hline 10 & 355 & Bangladesh & 105 & 18 & 35 & 21 \\
\hline 11 & 332 & Mexico & 105 & 16 & 44 & 26 \\
\hline 12 & 382 & Mexico & 105 & 17 & 38 & 26 \\
\hline 14 & 402 & Mexico & 105 & 16 & 35 & 25 \\
\hline 15 & 143 & Poland & 105 & 25 & 42 & 39 \\
\hline
\end{tabular}




\begin{tabular}{|l|l|l|l|l|l|l|}
\hline 16 & 366 & Hungary & 105 & 16 & 39 & 25 \\
\hline
\end{tabular}

Samples from Australia, USA, Pakistan, Bangladesh, Mexico and Poland had a growth period of 105 days, i.e. maturing simultaneously with the standard variety. The growth period of Ethiopian and Sudanese specimens was 108-110 days, with ripening 3-5 days later than normal.

When studying the results of the analysis of the average number of seeds in a single crop basket of plants, the average number of seeds in a single crop basket of the standard 114 variety was 39 , and the weight of 1000 seeds was 39 grams.

Of the 100 samples of safflower, 40 (43-63) were higher than the standard variety, 13 (39-41) were equal, and the remaining 47 (31-38) were low-seeded (Table 4).

According to the number of seeds in the harvest basket, 8 samples were selected from Kazakhstan (k-461, k-463, k-464, k-478, k-79, k-480, k-493), and 3 from Mexico (k- 298, k- 322, k-351), from one sample -Ethiopia (k-54), Pakistan (k-255), Azerbaijan (k-249), Australia (k-195). Ethiopia (k-54), Australia (k-195) and the United States (k-336), averaged -45 pieces per sample basket, k-255 (Pakistan) -46 pieces, k-249 (Azerbaijan) -47 pieces, k-322, k-298, k-351 (Mexico) -48-56 pieces and Kazakhstan (k-458, k-461, k-463, k-464, k-478, k-479, k-480 and 493) samples contained 53-63 seeds.

The number of seeds in the harvest baskets of these specimens varied from 6 to 14 compared to the standard variety. However, although the number of seeds in the crop baskets of k-336 (USA), k-249 (Azerbaijan) and k-298 (Mexico) was large, it was found that one plant yielded less than the standard variety due to the weight of 1000 seeds weighing 28-38 grams. 
Table 4. Main economic characteristics of safflower samples selected by the number of seeds in one crop basket (2011-2014)

\begin{tabular}{|c|c|c|c|c|c|}
\hline \# & 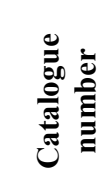 & 获 & 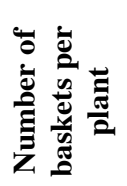 & 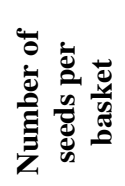 & 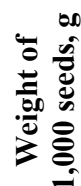 \\
\hline 1 & 114 (st) & Uzbekistan & 11 & 39 & 39 \\
\hline 2 & 54 & Ethiopia & 16 & 45 & 41 \\
\hline 3 & 336 & USA & 21 & 45 & 38 \\
\hline 4 & 195 & Australia & 24 & 45 & 40 \\
\hline 5 & 255 & Pakistan & 27 & 46 & 46 \\
\hline 6 & 249 & Azerbaijan & 8 & 47 & 37 \\
\hline 7 & 298 & Mexico & 10 & 56 & 28 \\
\hline 8 & 322 & Mexico & 14 & 48 & 42 \\
\hline 9 & 351 & Mexico & 14 & 52 & 38 \\
\hline 10 & 458 & Kazakhstan & 11 & 51 & 42 \\
\hline 11 & 461 & Kazakhstan & 11 & 54 & 42 \\
\hline 12 & 463 & Kazakhstan & 9 & 53 & 43 \\
\hline 13 & 464 & Kazakhstan & 12 & 53 & 43 \\
\hline 14 & 478 & Kazakhstan & 7 & 50 & 47 \\
\hline 15 & 479 & Kazakhstan & 7 & 50 & 41 \\
\hline 16 & 480 & Kazakhstan & 6 & 55 & 39 \\
\hline 17 & 493 & Kazakhstan & 9 & 63 & 39 \\
\hline
\end{tabular}

The average correct correlation between the number of seeds in the seed baskets and the number of crop baskets in the plant $(\mathrm{r}=0.30)$ is weak, and the average correct correlation between the number of seeds in the seed baskets and the seed size $(r=0.40)$. The presence of a correlation was determined.

Among the selected specimens, the k-255 (Pakistan) sample, the average number of seeds per seed basket (46), the weight of 1000 seeds ( $46 \mathrm{~g}$ ), the number of seed baskets per plant (27 pieces) were higher than the standard and other samples. In particular, there is an opportunity to create a new high-yielding variety suitable for the climatic conditions of the republic in a short period of time on the basis of individual and family selection by involving this sample in the process of analytical selection. 
Seed size is one of the important quality indicators in the processing of safflower seeds. This is because the production of quality edible oil for food from safflower seeds requires the separation of the seed coat. The oil obtained by grinding with the peel of Safflower seeds has a bitter taste and is suitable only for use in the paint industry.

It is relatively easy to separate large seeds from the husk, which can be done on the basis of technology adapted to sunflower. Of the 100 safflower samples studied for primary seed production to create large-seeded varieties, 40 were higher than the standard variety (40-47 g) and 10 were almost identical to the standard variety. $39 \mathrm{~g})$ and 50 were observed to have lower (28-38 g) results than the standard variety (Table 5).

Safflower's k-25, k-47, (Uzbekistan), k-228 (Ethiopia), k-323, k-385 (Mexico), k-273, k-209 (Australia), k-362, k-365 (Hungary), k-482, k-483 (Kazakhstan) samples weighing 1000 seeds $-44 \mathrm{~g}$; $-45 \mathrm{~g}$ in samples k-498 (Kazakhstan), k-303 (Spain), k-321, k-317 (Mexico), k-259 (Morocco) and k-57 (Ethiopia); $46 \mathrm{~g}$ in samples k-382 (Mexico), k-339 (Portugal), k-477, k-495 (Kazakhstan); The k-478, k-496 (Kazakhstan), k-248 (Afghanistan), k-213 (South Africa), k-182 (Morocco) and k-66 (Egypt) samples yielded 47 g.

Table 5. Seed samples separated by seed size

\begin{tabular}{|c|c|c|c|c|c|}
\hline \# & 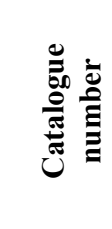 & 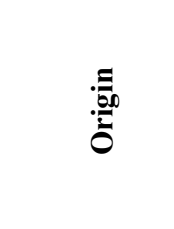 & 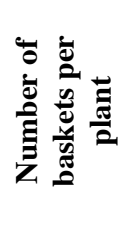 & 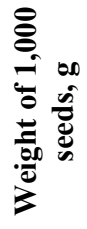 & 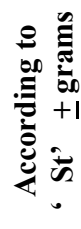 \\
\hline 1 & 114 (st) & Uzbekistan & 11 & 39 & \\
\hline 2 & 25 & Uzbekistan & 16 & 44 & +5 \\
\hline 3 & 47 & Uzbekistan & 13 & 44 & +5 \\
\hline 4 & 54 & Ethiopia & 16 & 44 & +5 \\
\hline 5 & 57 & Ethiopia & 19 & 45 & +6 \\
\hline 6 & 66 & Egypt & 13 & 47 & +8 \\
\hline 7 & 182 & Marocco & 11 & 47 & +8 \\
\hline 8 & 209 & Australia & 16 & 44 & +5 \\
\hline 9 & 213 & South Africa & 13 & 47 & +8 \\
\hline 10 & 248 & Afghanistan & 15 & 47 & +8 \\
\hline 11 & 259 & Morocco & 15 & 45 & +6 \\
\hline 12 & 303 & Spain & 12 & 45 & +6 \\
\hline 13 & 317 & Mexico & 12 & 45 & +6 \\
\hline 14 & 321 & Mexico & 13 & 45 & +6 \\
\hline
\end{tabular}




\begin{tabular}{|c|c|c|c|c|c|}
\hline 15 & 323 & Mexico & 13 & 44 & +5 \\
\hline 16 & 339 & Portugal & 14 & 46 & +7 \\
\hline 17 & 362 & Hungary & 14 & 44 & +5 \\
\hline 18 & 365 & Hungary & 13 & 44 & +5 \\
\hline 19 & 382 & Mexico & 17 & 46 & +7 \\
\hline 20 & 385 & Mexico & 11 & 44 & +5 \\
\hline 21 & 477 & Kazakhstan & 9 & 46 & +7 \\
\hline 22 & 478 & Kazakhstan & 7 & 47 & +8 \\
\hline 23 & 483 & Kazakhstan & 7 & 44 & +5 \\
\hline 24 & 495 & Kazakhstan & 7 & 46 & +7 \\
\hline 25 & 496 & Kazakhstan & 8 & 47 & +8 \\
\hline 26 & 498 & Kazakhstan & 9 & 45 & +6 \\
\hline
\end{tabular}

These samples are large-seeded and it can be seen from Table 5 that the weight of 1000 seeds is 5-7 grams higher than the standard variety.

K-25, (Uzbekistan), k-54, k-57 (Ethiopia), k-382 (Mexico), k-259 (Morocco), k-209 (Australia) and k-248 Afghanistan) specimens were also distinguished by the number of baskets per plant per plant, with 4-8 baskets more than the standard. The seeds of the samples introduced from Kazakhstan were larger than the other samples and it was observed that the number of harvest baskets on one plant was very small (7-9 pieces).

When the data obtained from the study were analyzed, it was found that there was an average correct correlation $(\mathrm{r}=0.40)$ between the seed size and the number of harvest baskets (see Table 8). It was observed that the larger the seeds, the lighter the color changed from light grey to white.

The safflower plant is grown mainly for the production of vegetable oil and is one of the most important economic brands. The oil content of the seeds of the model -114 averaged $38 \%$, in 40 of the studied samples the oil content was $35-37 \%$, in $29-38-39 \%$, and in $31-$ $40-46 \%$.

The oil content of the seeds (relative to dry biomass) is k-54 (Ethiopia), k-165 (Sudan), k-209 (Australia), k-327 (USA), k- (Pakistan), k-323 (Mexico), -41\% in k-67 (France) samples; K-56 of Ethiopia; k-57; k-172, Australia's k-193, Pakistan's k-255; k-345, Azerbaijan k-249, Mexico k-321 -42\% and Portugal k-339 46\%. Or, the oil content of the seeds in this sample is K-54 (Ethiopia), k-165 (Sudan), k-209 (Australia), k-327 (USA), k(Pakistan), k-323 (Mexico) compared to the standard variety. ), k-67 (France) $-107 \%$ in samples; K-56 of Ethiopia; k-57; k-172, Australia's k-193, Pakistan's k-255; k-345, Azerbaijan k-249, Mexico k-321 -110\% and Portugal k-339 121\% higher (Table 6). 
Table 6. Maximum samples with high fat content in seeds (2017-2019)

\begin{tabular}{|c|c|c|c|c|c|}
\hline \# & 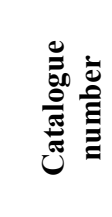 & 葋 & 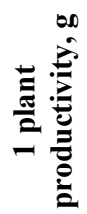 & 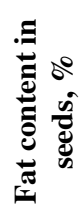 & 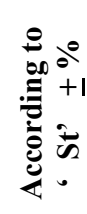 \\
\hline 1 & $114(\mathrm{st})$ & Uzbekistan & 17 & 38 & 100 \\
\hline 2 & 54 & Ethiopia & 25 & 41 & 107 \\
\hline 3 & 56 & Ethiopia & 15 & 42 & 110 \\
\hline 4 & 57 & Ethiopia & 25 & 42 & 110 \\
\hline 5 & 67 & France & 15 & 41 & 107 \\
\hline 6 & 143 & Poland & 39 & 42 & 126 \\
\hline 7 & 165 & Sudan & 33 & 41 & 107 \\
\hline 8 & 172 & Ethiopia & 12 & 42 & 110 \\
\hline 9 & 193 & Australia & 16 & 42 & 110 \\
\hline 10 & 209 & Australia & 21 & 41 & 107 \\
\hline 11 & 215 & Turkey & 21 & 41 & 107 \\
\hline 12 & 249 & Azerbaijan & 21 & 42 & 110 \\
\hline 13 & 252 & Pakistan & 19 & 41 & 107 \\
\hline 14 & 255 & Pakistan & 27 & 42 & 110 \\
\hline 15 & 321 & Mexico & 25 & 42 & 110 \\
\hline 16 & 323 & Mexico & 25 & 41 & 107 \\
\hline 17 & 327 & USA & 24 & 41 & 107 \\
\hline 18 & 339 & Portugal & 22 & 46 & 121 \\
\hline 19 & 345 & Pakistan & 18 & 42 & 110 \\
\hline 20 & 355 & Bangladesh & 21 & 41 & 107 \\
\hline 21 & 372 & Hungary & 15 & 42 & 126 \\
\hline
\end{tabular}

When analyzing the samples of the world collection introduced from different countries by region, the oil content in the seeds of samples from Central Asia (Uzbekistan, Kazakhstan) was $-37 \%$, in samples from Northeast Africa (Ethiopia, Sudan, Egypt, 
Morocco and South Africa). -39\%, in the Southern Hemisphere (Australia) -41\%; In North and South America - 39\%; South Asia (Pakistan, Bangladesh) -40\%; In South-West Asia (Afghanistan, Azerbaijan) - 39\%; South-Western Europe (France, Spain and Portugal) $41 \%$, Central Europe (Poland, Czechoslovakia, Germany, Hungary) $-39 \%$, samples from South-West Asia and Southeast Europe (Turkey and Bulgaria) - 40\% formed.

K-25 (Uzbekistan), k-54, k-57 (Ethiopia), k-259 (Morocco), k-221, k-235, which were simultaneously distinguished by several valuable economic features from the samples studied in the course of research on complex traits, (Mexico) and k-339 (Portugal, k-255 (Pakistan), k-143 (Poland) were selected. These samples ranged from 5 to 22 grams per plant yield per 1000 seed weight per standard 114 navigator and showed high results at 2-7 grams and $3-8 \%$ in seed oil content (Table 7).

Table 7. Main valuable economic features of the samples of safflower selected on the basis of complex features (2017-2019)

\begin{tabular}{|c|c|c|c|c|c|c|c|c|}
\hline \# & 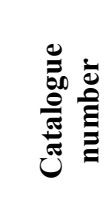 & 葛 & 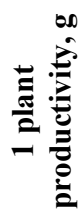 & 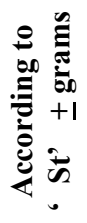 & 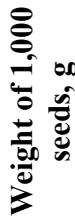 & 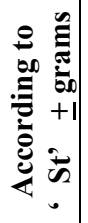 & 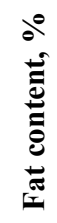 & 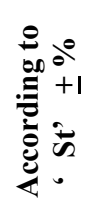 \\
\hline 1 & 114 (st) & Uzbekistan & 17 & 0 & 39 & 0 & 38 & 0 \\
\hline 2 & 54 & Ethiopia & 25 & 8 & 41 & 2 & 41 & 3 \\
\hline 3 & 57 & Ethiopia & 31 & 14 & 45 & 6 & 42 & 4 \\
\hline 4 & 165 & Sudan & 33 & 16 & 42 & 3 & 41 & 3 \\
\hline 5 & 255 & Pakistan & 27 & 10 & 42 & 3 & 42 & 4 \\
\hline 6 & 221 & Mexico & 25 & 8 & 45 & 6 & 42 & 4 \\
\hline 7 & 325 & Mexico & 25 & 8 & 44 & 5 & 41 & 3 \\
\hline 8 & 339 & Portugal & 22 & 5 & 46 & 7 & 46 & 8 \\
\hline 9 & 143 & Poland & 39 & 22 & 43 & 4 & 42 & 4 \\
\hline
\end{tabular}

The correlation of the main traits was also analyzed when the samples of the world collection of Safflower were studied for valuable economic characteristics, and the following results were obtained, including: length of the main stem with the duration of the growing season $(r=0.15)$, height to the first crop branch $r=(0.18)$, side branches, number of secondary branches $(\mathrm{r}=0.12 ; 0.14)$, diameter of seed baskets $(\mathrm{r}=0.14)$, amount of oil in seeds $(r=0.14)$, weight of 1000 seeds $(r=0.24)$ and a weak direct correlation between the number of seeds in a basket $(\mathrm{r}=0.20)$ was observed, while the average correct correlation between a plant yield $(\mathrm{r}=0.60)$ was found (Table 8$)$. 
Table 8. Correlation between the economic characteristics of safflower

\begin{tabular}{|c|c|c|c|c|c|c|c|c|c|c|}
\hline & 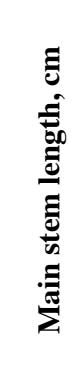 & 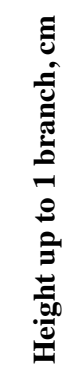 & 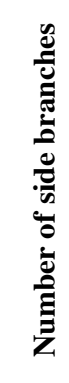 & 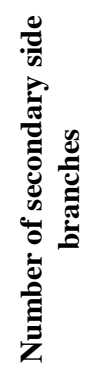 & 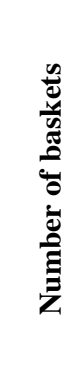 & 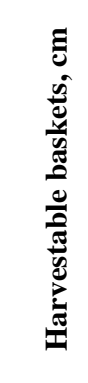 & 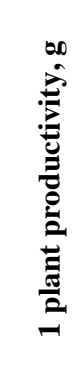 & 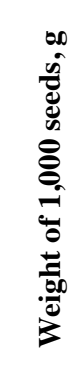 & 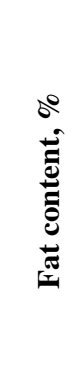 & 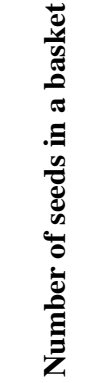 \\
\hline $\begin{array}{c}\text { Growing } \\
\text { date, days }\end{array}$ & 0.15 & 0.18 & 0.12 & 0.14 & 0.08 & 0.14 & 0.60 & 0.24 & 0.14 & 0.20 \\
\hline \multicolumn{2}{|c|}{$\begin{array}{c}\text { Main stem length, } \\
\text { cm }\end{array}$} & 0.84 & 0.30 & 0.25 & 0.13 & 0.30 & 0.39 & 0.13 & 0.24 & 0.20 \\
\hline \multicolumn{2}{|c|}{$\begin{array}{l}\text { Height up to } 1 \\
\text { branch, cm }\end{array}$} & & 0.18 & -0.07 & -0.20 & -0.33 & -0.23 & -0.19 & 0.08 & -0.18 \\
\hline \multicolumn{2}{|c|}{$\begin{array}{c}\text { Number of side } \\
\text { branches }\end{array}$} & & & 0.34 & 0.41 & -0.10 & 0.51 & 0.02 & 0.10 & -0.02 \\
\hline \multicolumn{2}{|c|}{$\begin{array}{c}\text { Number of } \\
\text { secondary side } \\
\text { branches }\end{array}$} & & & & 0.90 & -0.38 & 0.70 & -0.02 & 0.24 & -0.39 \\
\hline \multicolumn{2}{|c|}{ Number of baskets } & & & & & -0.31 & 0.72 & 0.40 & 0.30 & 0.30 \\
\hline \multicolumn{2}{|c|}{$\begin{array}{l}\text { Harvestable } \\
\text { baskets, cm }\end{array}$} & & & & & & 0.03 & 0.40 & -0.48 & 0.55 \\
\hline \multicolumn{2}{|c|}{$\begin{array}{c}1 \text { plant } \\
\text { productivity, } g\end{array}$} & & & & & & & 0.04 & 0.23 & 0.27 \\
\hline \multicolumn{2}{|c|}{$\begin{array}{l}\text { Weight of } 1,000 \\
\text { seeds, } g\end{array}$} & & & & & & & & -0.01 & -0.25 \\
\hline \multicolumn{2}{|c|}{$\begin{array}{c}\text { Number of seeds in } \\
\text { a basket }\end{array}$} & & & & & & & & & -0.34 \\
\hline
\end{tabular}

The average correct correlation between the number of side branches in a plant and the number of secondary side branches $(r=0.34)$, the number of total yield baskets $(r=0.41)$, and the signs of a plant yield $(r=0.51)$, with one plant yield it was noted that there was a strong direct correlation between the number of secondary side branches $(r=0.70)$ and the number of harvested baskets $(\mathrm{r}=0.72)$.

There is an average correct correlation between the number of seeds in a basket and the average diameter of the baskets $(r=0.55)$ and the number of secondary side branches with the average number of seeds in a single basket $(r=-0.39)$ and the weight of 1000 seeds $(r=$ -0.25 ) was found to have an average inverse correlation.

The highest correct correlation was observed between the length of the main stem and the length up to 1 branch $(r=0.84)$ and the total number of baskets in one plant with the number of secondary side branches in it $(\mathrm{r}=0.90)$. It was observed that in which plants the number of secondary crop baskets was higher, the total number of baskets also increased accordingly.

The relationship between the diameter of the seed baskets and the weight of 1000 seeds is weak $(r=0.18)$, except for the diameter of the seed baskets $(r=-0.48)$ and the weight of 
1000 seeds $(r=-0.01)$. The presence of a weak correct correlation between all the other studied characters was determined on the basis of the analyzes.

\section{Conclusion}

Based on the study of 100 specimens of safflower introduced from different countries of the world on morpho-biological and valuable economic characteristics, 4 on the main stem height, k-411 (Egypt), k-193 (Australia), k-351 (Mexico) and k-262 (Poland) samples were isolated. These samples serve as a primary source for selection of new varieties suitable for creating a vitamin-rich feed base for tomorrow's livestock.

Mexico (k-299, k-313, k-316, 317), Spain (k-303, k-337), Portugal (k-339) and Kazakhstan (k-477, k-478), separated by maturity, k-479) were found to be physiologically mature 5-7 days earlier than the standard variety.

K-25, k-47, (Uzbekistan), k-228 (Ethiopia), k-382, k-317, k-323, k-385 (Mexico), k273, k- 209 (Australia), k-362, k-365 (Hungary), k482, k-483, k-498 (Kazakhstan), k-303 (Spain), k-321, k-182; k-259 (Morocco, k-57 (Ethiopia), k-339 (Portugal), k-478, k-496, k477, k-495 (Kazakhstan), k-248 (Afghanistan), k-213 in the samples of South Africa) and k-66 (Egypt) the weight of 1000 seeds is $44-47$ grams (5-7 grams higher than the standard variety) and serves as a primary source in the creation of promising varieties for confectionery and consumer oil production.

Eight samples were selected for the complex, including two from Mexico and Ethiopia, and one from Sudan, Portugal and Poland, which are unique sources for the creation of new promising varieties in the short term by synthetic selection.

With the duration of the growing season, the length of the main stem $(r=0.15)$, the height to the first harvest branch $(\mathrm{r}=0.18)$, the number of side branches, the number of secondary branches $(r=0.12 ; 0.14)$, the diameter of the harvest baskets $(r=0.14)$, the amount of oil in the seed $(r=0.14)$, the weight of 1000 seeds and a weak correct correlation between the number of seeds in one basket, while the average correlation between plant yield $(r=0.60)$ found to have a correlation.

The average correct correlation between the number of side branches in a plant and the number of secondary side branches $(r=0.34)$, the total yield number $(r=0.41)$ and the signs of a plant yield $(r=0.51)$ is secondary to the plant yield per plant. It was noted that there is a strong correlation between the number of side branches $(r=0.70)$ and the number of harvested baskets $(r=0.72)$.

The highest correlation was observed between the length of the main stem and the length up to 1 branch $(r=0.84)$ and the total number of baskets in one plant with the number of secondary side branches in it $(r=0.90)$.

\section{References}

1. M. E. Amanova, Actual problems of modern science 5, 197-202 (2018)

2. S. Isaev, I. Begmatov, G. Goziev, S. Khasanov, IOP Publishing 883(1), 012080 (2020)

3. S. K. Isaev, R. U. Rakhmonov, S. S. Tadjiev, G. I. Goziev, S. Z. Khasanov, IOP Publishing 614(1), 012147 (2020)

4. SH. Oripov, Agro-knowledge 2(52), 22-26 (2018)

5. A. A. Yassein, A. E. Khalaf, A. A. Mohdaly, M. H. Roby, OCL 27, 66 (2020)

6. H. Ambreen, S. Kumar, A. Kumar, M. Agarwal, A. Jagannath, S. Goel, Frontiers in plant science 9, 402 (2018)

7. A. Diederichsen, Plant Breeding 120(4), 360-362 (2008) 
8. S. N. Chandrawati, R. Kumar, Physiol Mol Biol Plants 23, 207-219 (2017)

9. P. Golkar, S. Karimi, In: Advances in Plant Breeding Strategies: Industrial and Food Crops, 537-575 (2019)

10. N. A. Nagre, V. L. Gawande, R. D. Ratnaparkhi, S. S. Nichal, Journal of Research ANGRAU 46(2), 40-45 (2018)

11. Y. S. Belete, Plant Gene and Trait, 8 (2017)

12. A. Farooq, S. A. Bukhari, N. A. Akram, M. Ashraf, L. Wijaya, M. N. Alyemeni, P. Ahmad, Plants 9(1), 104 (2020)

13. B. Wei, K. Hou, H. Zhang, X. Wang, W. Wu, Industrial Crops and Products 151, $112465(2020)$ 